\title{
Over expression of HER2/neu in female ductal carcinoma: Pure invasive versus invasive with in situ component
}

\author{
Mohamed Salah Abdelhamid ${ }^{1}$, Ahmed Mohamed Sadat ${ }^{1}$, Mohamed Salah Abdelbasset ${ }^{1}$, \\ Amr Mohamed Aly Mohamed ${ }^{1}$, Hesham Ahmed Abdel Wahab Nafady, \\ Khald Mohamed Shawky ${ }^{1}$, Solafa Amin Abdelaziz ${ }^{2}$, Lobna Omar El Farouk Abd Elsalam², \\ Mahmoud Ahmed Negida ${ }^{2}$, Reham Shehab El Nemr Esmail ${ }^{3}$, Adel Morad Abdellah ${ }^{4}$, \\ Ahmed Zaki Gharib ${ }^{4}$
}

${ }^{1}$ Bani Suef Faculty of Medicine, Bani Suef University, Egypt

${ }^{2}$ Kasr El Aini Faculty of Medicine, Cairo University, Egypt

${ }^{3}$ National Research Center, Cairo University, Egypt

${ }^{4}$ October 6th Faculty of Medicine, October 6th University, Cairo, Egypt

\section{Email address:}

mohamedsalah_2000@hotmail.com (M. S. Abdelhamid)

\section{To cite this article:}

Mohamed Salah Abdelhamid, Ahmed Mohamed Sadat, Mohamed Salah Abdelbasset, Amr Mohamed Aly Mohamed, Hesham Ahmed Abdel Wahab Nafady, Khald Mohamed Shawky, Solafa Amin Abdelaziz, Lobna Omar El Farouk Abd Elsalam, Mahmoud Ahmed Negida, Reham Shehab El Nemr Esmail, Adel Morad Abdellah, Ahmed Zaki Gharib. Over Expression of HER2/Neu in Female Ductal Carcinoma: Pure Invasive Versus Invasive with in Situ Component. Journal of Surgery. Vol. 2, No. 6, 2014, pp. 105-108. doi: 10.11648/j.js.20140206.16

\begin{abstract}
Aims: We are trying to understand the role of HER 2 neu in tumor progression. Study design: Prospective study. Place and duration: Conducted at Bani Swif and Kasr AL Aini university hospitals between May 2013 and May 2014. Methodology: 32 patients were enrolled in the study. The speceimens were obtained surgically .Expression of HER-2-neu receptors done aided with Dako Code No. A0485. Results: In the study there were 15 cases with pure invasive carcinoma and 17 cases with in situ component, there were more positive cases $(59 \%)$ with HER-2-neu in the invasive associated with in situ group than those in the pure invasive group $(20 \%)$, this was statistically significant $(\mathrm{P}<0.016)$. Conclusion: In conclusion, it may be assumed that during cells of the in situ component are acquiring invasiveness, they partly loose Her-2-neu over expression The high percent of positive HER-2-neu in cases associated with in situ component point an arrow with question mark towards possible changes in the tumor cell biology or the actual cell line of the in situ and the invasive components.
\end{abstract}

Keywords: Mammary, Invasive, In Situ, Carcinoma

\section{Introduction}

Development of breast cancer may be due to activation or amplification of oncogenes [1]. In breast cancer, most altrations have been located at chromosomal positions 1q, 8p12, 8q24, 11q13, 12p13, 16p13, 7q12-21 and 20q13, and many oncogenes have been identified [2-5]. The most famous oncogene is HER2, located at 17q12-21, which is overexpressed in 15 to $20 \%$ of breast cancers [6]. In mammary epithelial cell, colostrums and milk, are rich source of growth factors [7]. Growth factors play role in mammary carcinogenesis. Steroid hormones strongly regulates certain growth factors [8]. Tumor formation occurs through a series of cellular signaling events, regulated by growth factors. Transformation of normal cells to malignant may happen as a result from alteration between stimulatory growth factors and inhibitory growth factors [9].

Altered expression of growth factor receptors affects normal growth. Activation of a growth factor receptor or an increase in receptor number has the same effect. The erb B oncogene product is a transmembrane receptor similar to the EGF receptor [9]. The c-erb-B-2 (HER2/neu) proto-oncogene is located on $17 \mathrm{q} 21$ chromosome, It is amplified and/or over expressed in approximately $30 \%$ of human breast tumors. Over expression is coupled with more aggressiveness, increased recurrence, and increased mortality in node positive patients, while the effect in node negative patients is variable. It may also have a role in the response to chemotherapy, endocrine therapy and resistance to alkylatorbased chemotherapy [10]. 
Excess copies of the HER 2 gene are associated in more than $90 \%$ of cases with increased expression or over expression of the HER 2 receptors. [11].

In this study we aimed at trying to understand the role of HER 2 neu in tumor progression.

\section{Patients and Methods}

This study was conducted at Bani Swif and Kasr Al Aini university hospitals from May 2013 to May 2014. Thirty two female patients were included in the study, with breast mass presented in the out patient department, none of those masses were discovered through any medical organized programme. All patients were subjected to routine preoperative assessment with treating of any co-morbid disease. The initial procedures were lumpectomy or quadrantectomy. The definitive procedure was modified radical mastectomy. All the specimens were examined macroscopically to access the site, size, absence or presence of other mass. Microscopic examination with haematoxylin and eosin stains for histological typing is done to document if it is accompanied by in situ component or is totally invasive.

Detection of HER-2-neu receptors done using Dako Code No. A0485, this antibody labels an intra cellular domain of cerb B-2 oncoprotein. The antibody can be used on paraffin sections fixed in formalin. Heat induced epitope retrieval in $10 \mathrm{mmol} / \mathrm{L}$ citrate buffer, pH6.0 or in Dako Target Retrieval Solution, Code No. S,1700. Cells labeled specifically by the antibody display a staining confined to the cell membrane. The staining intensity was graded as negative(0) mild(1) moderate(2) and strong (3), [12].

Statistical analysis is done using Fisher's test to obtain the $\mathrm{Z}$-value and from the standardized table the degree of propability is obtained [13].

\section{Results}

Thirty two females patients included in the study, their ages ranged from 25 years to 75 years with a mean $+\mathrm{SD}$ of 48 years +13.5 years.

17 cases were diagnosed as invasive duct carcinoma having in situ component, ten out of them showed her2neu over expression (59\%). The staining of the insitu component in the positive cases (10/17) mostly showed continues complete membranous pattern. The intensity of the staining ranged from moderate to strong. On the other hand, in the invasive component, most of the positive tumor cells showed incomplete membranous staining pattern and the staining intensity was only mild to moderate.

15 cases were diagnosed as pure invasive duct carcinoma. Only three of them showed Her2neu over expression (20\%). The majority of the tumor cells showed incomplete membranous staining pattern with mild to moderate staining intensity.

The difference between the two groups studied was statistically significant $(\mathrm{P}<0.016)$.

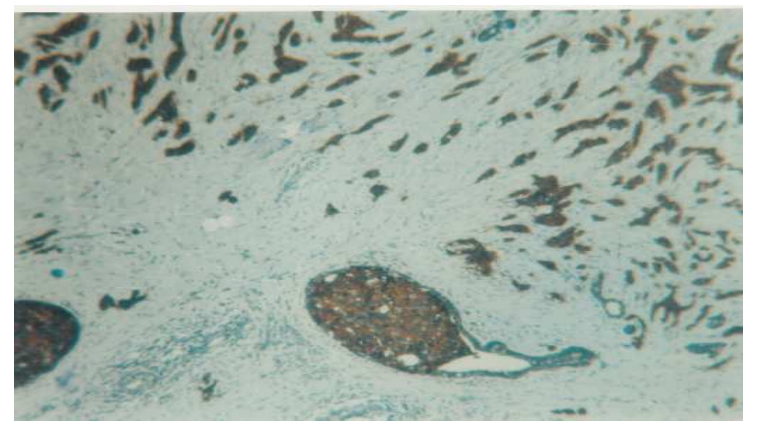

Fig 1. Infiltrating duct carcinoma with intra ductal component showing strongly positive reaction for HER - 2 neu (X 100)

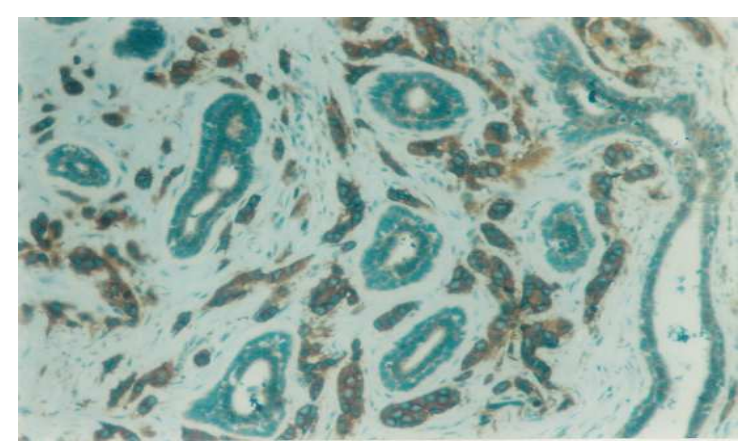

Fig 2. Infiltrating duct carcinoma with moderate to strong positive staining for HER - 2neu receptors, compared to negative staining reaction seen in the intervening normal non neoplastic glands(x100)

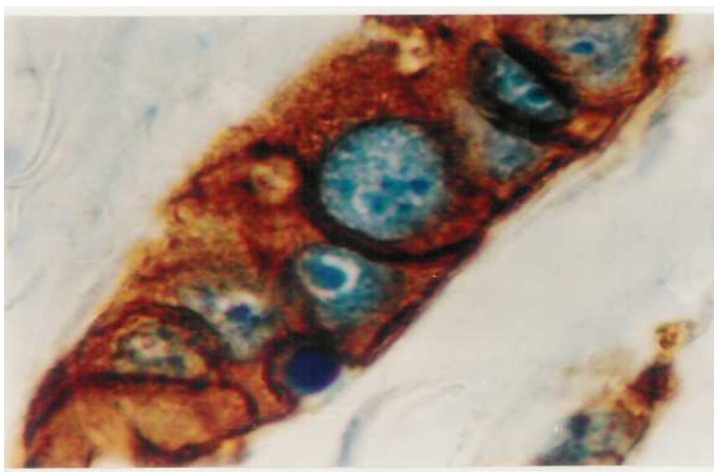

Fig 3. Infiltrating duct carcinoma with strongly positive staining for HER 2 neu. Note the strong complete membranous staining (X 1000)

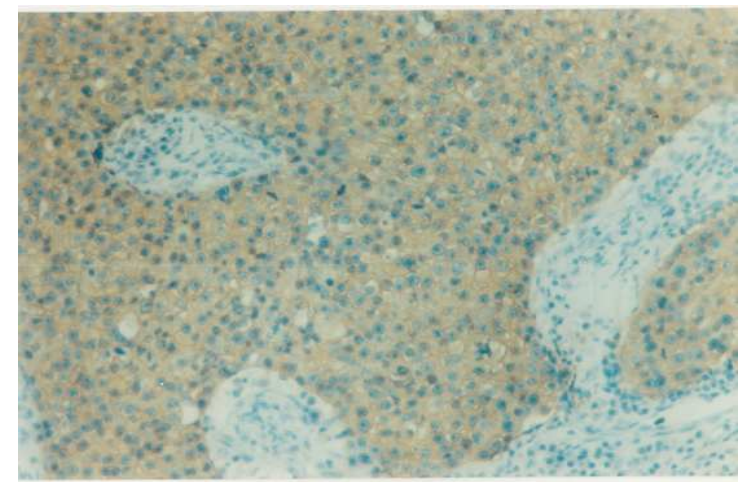

Fig 4. Infiltrating duct carcinoma with mild positive staining reaction to HER - 2 neu receptors ( X 250 ) 


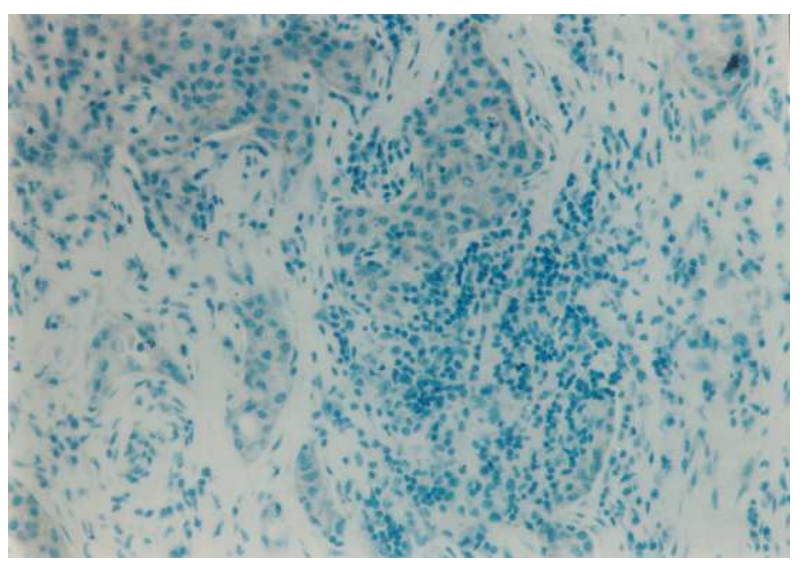

Fig 5. Infiltrating duct carcinoma with negative staining reaction to HER 2 neu receptors. Note: considerable lymphocytic infiltrate (X 100)

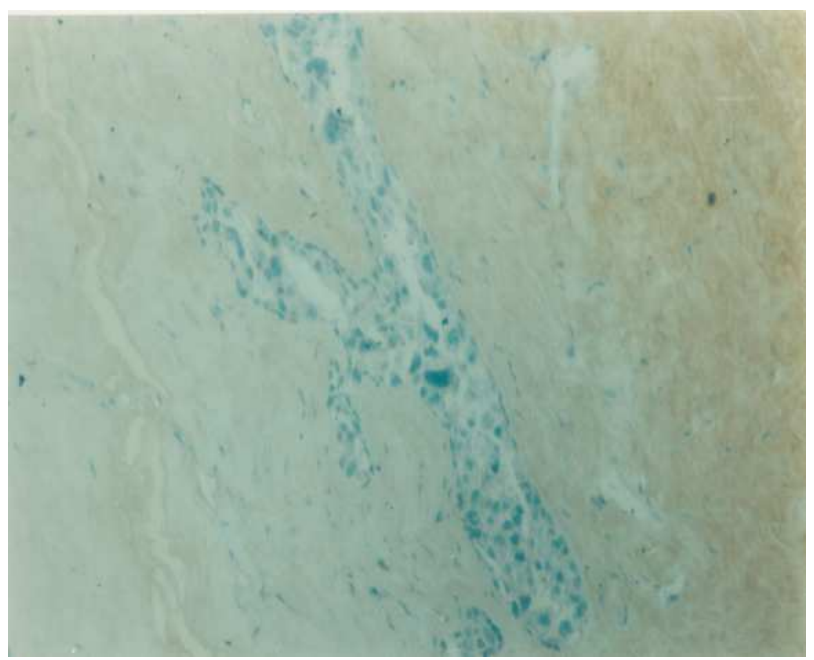

Fig 6. Intraductal carcinoma exhibiting negative immunostaining reaction for HER 2 neu receptors (X 100)

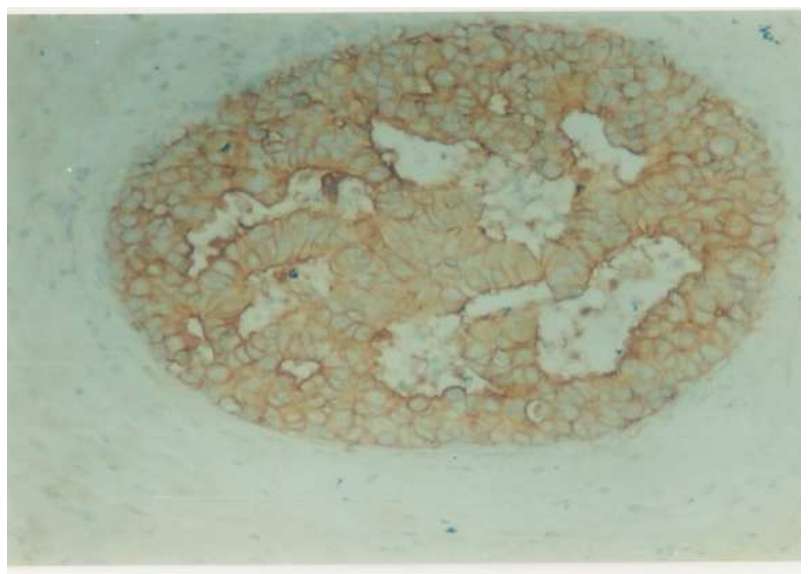

Fig 7. Intraductal carcinoma with moderate staining for HER - 2 neu (X 250)

Table 1. HER-2-neu over expression

\begin{tabular}{lllll}
\hline Invasion & No & $\begin{array}{l}\text { HER-2 } \\
\text { Positive }\end{array}$ & $\begin{array}{l}\text { HER-2 } \\
\text { Negative }\end{array}$ & Statistics \\
\hline $\begin{array}{l}\text { With in situ } \\
\text { component }\end{array}$ & $17(53 \%)$ & $10(59 \%)$ & $7(41 \%)$ & $\begin{array}{l}\mathrm{Z}=2.48 \\
\mathrm{P}=0.016 \\
\mathrm{P}=0.016 \\
\text { Significant }\end{array}$ \\
\hline
\end{tabular}

\section{Discussion}

By the age of 85 one in nine women will develop breast carcinoma during her lifetime. With increased public awareness, more mammary carcinomas are detected, before axillary metastases. Two thirds of the invasive have with negative axilla. Recurrence will develop in about $20 \%$ to $30 \%$ of patients with node negative. Those $20 \%$ to $30 \%$ should be considered for aggressive adjuvant therapies. The remaining $70 \%$ to $80 \%$ need no further therapy. Pathologists can assess risk factors for development of recurrent tumor. These risk factors include lymph node status, size and type, histologic grade, lymphatic and vascular invasion, tumor proliferation and receptor status [11].

Concerning the insitu and the invasive breast cancer patients, in our study there were seventeen cases diagnosed as invasive associated with insitu component, there were fifteen cases diagnosed as pure invasive carcinoma, HER-2-neu was positive in 59\% in the insitu group compared to $20 \%$ in the invasive group, this difference was significant $(\mathrm{P}<0.016)$. Our findings are close to those of Schmitt et al [14] who demonstrated HER 2 neu over expression in $43.7 \%$ of intraductal carcinomas compared to $17.6 \%$ of invasive carcinoma. Again, in the study of Jang et al, HER2 gene amplification detected more in pure ductal carcinoma in situ (DCIS) than in invasive carcinomas (30.9\% versus. $19.9 \%, P=0.004)$, findings that are in agreement of our results. Jang et al also detected amplification in DCIS components cells but not in the invasive carcinoma components of the same tumor(15) This amplification was significantly more in pure DCIS than in invasive carcinomas, especially of the high-grade tumors, others have obtained the same values [16,17] The variation in the degree of Her2neu over expression, especially in the DCIS component may be explaind by that DCIS is a high heterogeneous growth with different histologic characteristics', molecular changes and risks of progress to invasive growth [18-19]. There appears to be at least two main groups of DCIS lesions: low-grade DCIS and high-grade DCIS [20-21].Analyses of specific cancer genes in matched DCIS and nearby invasive carcinomas, suggested that although the modal populations of both were similar at the genetic level, the progression from DCIS to invasive ductal carcinoma was conducted in some cases by selection of nonmodal clones with specific genetic defects [22]. It was expected that the high positivity of HER-2-neu in cases of insitu carcinoma will extend to have a higher positivity in the invasive component but the reverse is the case, this might raise the suspicion of the role of HER-2-neu in tumor genesis.

From the clinical point of view this may help in adjusting the treatment especially for those with in situ component who are in deep need for close follow up.

In conclusion, it may be assumed that during cells of the in situ component are acquiring invasiveness, they partly loose Her-2-neu over expression. The high percent of positive HER-2-neu in cases associated with insitu component point an arrow with question mark towards possible changes in the tumor cell biology or the actual cell line of the in situ and the invasive components. 


\section{References}

[1] Beckmann MW, Niederacher D, Schnurch HG, Gusterson BA, Bender HG. Multistep carcinogenesis of breast cancer and tumour heterogeneity. J Mol Med (Berl) 1997; 14:429-439. doi: 10.1007/s001090050128. [PubMed] [Cross Ref]

[2] Courjal F, Theillet C. Comparative genomic hybridization analysis of breast tumors with predetermined profiles of DNA amplification. Cancer Res. 1997; 14:4368-4377. [PubMed]

[3] Yao J, Weremowicz S, Feng B, Gentleman RC, Marks JR, Gelman R, Brennan C, Polyak K. Combined cDNA array comparative genomic hybridization and serial analysis of gene expression analysis of breast tumor progression. Cancer Res. 2006; 14:4065-4078. doi: 10.1158/0008-5472.CAN-054083.[PubMed] [Cross Ref]

[4] Adelaide J, Finetti P, Bekhouche I, Repellini L, Geneix J, Sircoulomb F, Charafe-Jauffret E, Cervera N, Desplans J, Parzy D, Schoenmakers E, Viens P, Jacquemier J, Birnbaum D, Bertucci F, Chaffanet M. Integrated profiling of basal and luminal breast cancers. Cancer Res. 2007;14:11565-11575. doi: 10.1158/0008-5472.CAN-07-2536. [PubMed] [Cross Ref]

[5] Nikolsky Y, Sviridov E, Yao J, Dosymbekov D, Ustyansky V, Kaznacheev V, Dezso Z, Mulvey L, Macconaill LE, Winckler W, Serebryiskaya T, Nikolskaya T, Polyak K. Genome-wide functional synergy between amplified and mutated genes in human breast cancer. Cancer Res. 2008;14:9532-9540. doi: 10.1158/0008-5472.CAN-08-3082. [PubMed] [Cross Ref]

[6] Press MF, Pike MC, Chazin VR, Hung G, Udove JA, Markowicz M, Danyluk J, Godolphin W, Sliwkowski M, Akita R, Paterson MC, Slamon DJ. Her-2/neu expression in node-negative breast cancer: direct tissue quantitation by computerized image analysis and association of overexpression with increased risk of recurrent disease. Cancer Res. 1993; 14:4960-4970. [PubMed]

[7] Grosvor CE and Picciano FC.: Hormones and growth factors milk. Endo Rev, 61:413-17, 1993.

[8] Vonderhaar BK.: Regulation of development of mammary gland. Cancer treat Res, 40:551-559, 1988.

[9] Daly JM, Bertagnolli M, Decosse JJ, et al.: Oncology. In Schwartz SI (ed) Principles of Surgery.: New York, MC GrowHill, pp 297-360, $7^{\text {th }}$ ed, 1999.

[10] Cianfrocca M and Goldstein LJ.: Prognostic and predictive factors in early stage breast cancer. The oncologist, 2004, 9 (6):606-616.

[11] Weiss LM.: Breast, in Weidner N, Cote RJ, Susters and Weiss LM (eds) Modern Surgical Pathology.: Philadelphia, Saunders pp 599-672, $1^{\text {st }}$ ed, 2003.

[12] Koeppen HKW, Wright BD, Burt AD, et al.: Over expression of HER-2-neu an immunohistochemical survey. Histopathology, 38:96-104, 2001.
[13] Swinscow TDV and Campell MJ.: statistics at square one. In Swinscow TDV (ed) Plymouth Latimer trend Company Ltd, pp 1-139 $9^{\text {th }}$ ed, 1996.

[14] Schmitt FC, Figueiredo P and Lacarda M.: Exxpression of Cerb B-2 protein and DNA ploidy in breast carcinogenesis. Arch Path Lab Med, 119 (9):815-20, 1995. Breast Cancer Res. 2012; 14(4): R115.

[15] Jang MH,Kim EJ, Choi Y ,Lee HE ,Kim YJ ,Kim JH ,Kang E, Kim SW, Kim IA, and Park SY .FGFRl is amplified during the progression of in situ to invasive breast carcinoma Published online Aug 3, 2012. doi: 10.1186/bcr3239

[16] Latta EK, Tjan S, Parkes RK, O'Malley FP. The role of HER2/neu overexpression/amplification in the progression of ductal carcinoma in situ to invasive carcinoma of the breast. Mod Pathol. 2002; 14:1318-1325. doi: 10.1097/01.MP.0000038462.62634.B1. [PubMed] [Cross Ref]

[17] Park K, Han S, Kim HJ, Kim J, Shin E. HER2 status in pure ductal carcinoma in situ and in the intraductal and invasive components of invasive ductal carcinoma determined by fluorescence in situ hybridization and immunohistochemistry. Histopathology. 2006; 14:702-707. doi: 10.1111/j.13652559.2006.02403.x. [PubMed] [Cross Ref]

[18] Erbas B, Provenzano E, Armes J, Gertig D. The natural history of ductal carcinoma in situ of the breast: a review. Breast Cancer Res Treat. 2006; 14:135-144. doi: 10.1007/s10549-005-9101-z. [PubMed][Cross Ref]

[19] Vincent-Salomon A, Lucchesi C, Gruel N, Raynal V, Pierron G, Goudefroye R, Reyal F, Radvanyi F, Salmon R, Thiery JP, Sastre-Garau X, Sigal-Zafrani B, Fourquet A, Delattre O. Integrated genomic and transcriptomic analysis of ductal carcinoma in situ of the breast. Clin Cancer Res. 2008; 14:1956-1965. doi: 10.1158/1078-0432.CCR-07-1465. [PubMed] [Cross Ref]

[20] Buerger H, Otterbach F, Simon R, Poremba C, Diallo R, Decker T, Riethdorf L, Brinkschmidt C, DockhornDworniczak B, Boecker W. Comparative genomic hybridization of ductal carcinoma in situ of the breastevidence of multiple genetic pathways. J Pathol. 1999; 14:396-402. doi: 10.1002/(SICI)10969896(199903)187:4<396::AID-PATH286>3.0.CO;2-L. [PubMed] [Cross Ref]

[21] Hwang ES, DeVries S, Chew KL, Moore DH, Kerlikowske K, Thor A, Ljung BM, Waldman FM. Patterns of chromosomal alterations in breast ductal carcinoma in situ. Clin Cancer Res. 2004; 14:5160-5167. doi: 10.1158/1078-0432.CCR-04-0165. [PubMed] [Cross Ref]

[22] Hernandez L, Wilkerson PM, Lambros MB, Campion-Flora A, Rodrigues DN, Gauthier A, Cabral C, Pawar V, Mackay A, A'Hern R, Marchio C, Palacios J, Natrajan R, Weigelt B, ReisFilho JS. Genomic and mutational profiling of ductal carcinomas in situ and matched adjacent invasive breast cancers reveals intra-tumour genetic heterogeneity and clonal selection. J Pathol. 2012; 14:42-52. doi: 10.1002/path.3990. [PubMed] [Cross Ref] 